\title{
A FLUOROPLANIGRAPHY SYSTEM FOR RAPID PRESENTATION OF SINGLE PLANE BODY SECTIONS*
}

\author{
Elliott C. Lasser, M.D. a, Norman A. Baily, Ph.D. ${ }^{b}$, and Ronald L. Crepeau, M.S." \\ Depariment of Radiology, University of Californio, San Diego \\ La Jolla, California 92037
}

\begin{abstract}
A single-scan TV radiography unit has been coupled to the moving film holder of a conventional overhead tube fluoroscopy unit so that it can be used in a tomographic mode. The method produces a true tomographic section which is presented immediately on the TV monitor. Field size and section thickness have been found to be satisfactory. The system allows rapid location of the plane and area of interest. Patient dose per exposure, when compared to fast film, for thick body parts was found to be reduced by approximately 7 to 55 times.

\section{KEY WORDS}

Fluoroplanigraphy, tomography, planigraphy, body section.

* This work partially supporied by NASA Grant No. NGL 05-009-103.

a Chairman and Professor, Department of Radiology, UCSD.

b Professor of Radiology, UCSD.

c Developmental Engineer, UCSD. 


\section{A FLUOROPLANIGRAPHY SYSTEM FOR RAPID PRESENTATION OF SINGLE PLANE BODY SECTIONS}

\section{INTRODUCTION}

The clinical usefulness of body section radiography is well established. These sections are usually produced by symchronized movements of both tube and film during the period of $x$-ray exposure. The use of film imposes certain restrictions on the method's utilization. First, a pilot study at the projected depth of interest must be done. Only after inspection of this pilot study and only affer suitable modifications for technique and position have been accomplished can an adequate definitive body section radiogram be obtained. This is time consuming and the dose to the patient is often excessive. If one atrempts to overcome this by multiple body plane radiographs produced by existing techniques, a certain degree of unsharpness is imposed by virtue of sccitter occurring along multiple screen and film interfaces. Further, the definitive plane of interest is often compromised because of patient movement during the interval of time necessary to make additional corrections and to view the resulting radiograms.

The use of a fluoroscopic presentation overcomes to a very large extent the difficulties outlined above by providing the radiologist with the capability of making adjustments in technique and position of the patient rapidly and accurately with a very reduced patient dose. Through the

use of a single-scan TV system ${ }^{1}$ with video disk recorder as a substitute for the usual film recording, we have been able to accomplish recording of true tomograms fluoroscopically.

The method presented produces a true romographic image identical to that seen on film. Unlike the method presented by Frimann-Dahl and $\mathrm{Kuhl}^{2}$ continuous motion and $\mathrm{x}$-ray input over a period of time sufficient to produce a stationary image is not required. Second, since the monitor is displaying a true tomographic section, it can be photographed and utilized as that portion of the completed study.

The method appears to have the potential for extension to studies of organs having 
associated motion. The image can be digitized and processed by computer for cither quantitative analysis or representation on video after edge enhancement, contrast enhancement, subtraction, etc.

\section{METHOD}

The basic roentgenographic equipment consists of a G.E. Model 73 horizontal table which was modified to accommodate a $9^{\prime \prime}-6$ "image intensifier undertable installation, hydraulically driven in conjunction with the x-ray tube (G.E. - B8190, Ordography BodySection atrachment). The image amplifier - TV chain was modified as described by Baker and Miller ${ }^{1}$ with the exception that at the same time as the readout beam is blanked, the target voltage is dropped to a negative 2 volts. This results in a greater signal-to-noise level and higher contrast images. The performance of a similar system (resolution and gray scale capabilities) has been described by Baily and Crepeau ${ }^{3}$. There are four travel amplitudes and two travel speeds available. These are: $6.25^{\prime \prime} ; 12.5^{11} ; 18.75^{11} ; 25^{\prime \prime} ;$ and $6.25^{\prime \prime} / \mathrm{sec}, 12.5^{\prime \prime} /$ sec., respectively. The focal spot to screen distance is $40 "$ ".

\section{RESULTS}

Since a fundamental difference between the use of film as a recording medium and the image amplif:er TV chain is the curvarure of the input phosphor, it is important to know the useable field size of the system. This was determined by establishing the in-focus plone at the center of the $x$-ray field and then moving the test object outward from the center until the in-focus layer was no longer sharp. The size of the central area in which the central plane of the in-focus layer appeared to remain constant was approximately circular and $3^{\prime \prime}$ in diameler.

The section thickness was determined through the use of a $1 \mathrm{~cm}$. thick lucite block having lead numbers spaced at imm. intervals in depti throughour its volume. The sechion thickness was then determined by visual examination of photographs taken of the TV monitor. The 
A FLUOROPLANIGRAPHY SYSTEM FOR RAPID PRESENTATION OF

SINGLE PLANE BODY SECTIONS

$-3-$

section thicknesses listed in Table 1 represent values af which image blurring has become visable to the eye. For comparison, the section thickness obtained using conventional film rechnigues are also given.

A most important aspect of the method is the large reduction in patient dose which con be achieved by the use of this system. Table 11 gives a comparison between exposure rates measured at $20 \mathrm{~cm}$. above the table top for both film and fluoro techniques utilized in our investigation of the system.

In addition to the test patiern, we have used a pelvic phantom and a patient to assess the diagnostic capabilities of the method. These are illustrated in the following four figures. Figure 1 illustrates a planigram recordec on film of the hip joint in a pelvic phantom. This film was recorded at $65 \mathrm{kVp}$ and $100 \mathrm{mAs}$ using a $12.5^{\prime \prime}$ stroke. Figure 2 is a photograph of the TV monitor showing the same section recorded by the fluoroplanigraphic system. The factors used were a 6.25 "stroke, $70 \mathrm{kVp}$, and $3.5 \mathrm{mAs}$. In oddition to the $6: 1$ built in grid, a $12.1 \mathrm{moving}$ grid was used. Figure 3 shows a planigram of the right thorax of a patient with metastices originating from a primary carcinoma of the cervix. This film was recorded using a $6.25^{\prime \prime}$ stroke, $70 \mathrm{kVp}$, and $25 \mathrm{mAs}$. Figure 4 shows the same section recorded by fluoroplanigraphy. The fachors used were $6.25^{\prime \prime}$ stroke, $70 \mathrm{kVp}$, and $1.5 \mathrm{mAs}$.

\section{DISCUSSION}

The use of the above described system which we have called fluoroplanigraphy mokes it possible to obtain static single-plane laminograms with far greater expediency than conventional laminograms. Second, these can be obtained with significant reduction in patient dose. Third, a large savings in operational time is effected. Trial and error projections can be accomplished in seconds rather than minutes and, therefore, it is possible to quickly optimize the alignment of the selected plane. Since there is a consiunt difference beiween the fulcrum seiring for the 


\section{$-4-$}

fluoroplanigram and conventional film planigram, the latter can be immediately obtained after the precise plane of interest has been selected from the fluoroscopic presentations. This should, therefore, increase the rotal urilization of the planigraphic procedure.

The system with some minor changes also offers the possibility for achieving dynamic fluoroplanigraphic studies. This can be accomplished by pulsing $x$-ray and recording units at fixed intervals of the planigraphic procedure. Rates up to 10 frames/sec. are possible; the limitation in the present system is a mechonical one, the rate at which the disk head con be moved. This apparatus will enable the examiner for the first time to assess pulsations or other forms of motion in a selected plone in the body. Immediate applications to the heat, vocal cords, and soft palate (in conjunction with speech disturbance studies) are suggested. It would also be anticipated that air studies of the subarachnoid spaces in the vertebral cancil and of the ventricles in the broin could be accomplished expeditiously and with new potential for the assessment of air bubble movement.

The limitation on usable field size is due to the curvoture of the image intensifier's input screen. The use of a unit with a flat screen would overcome this difficulty. However, it should be pointed out that the curvature has real benefit in that thin sections can be obtained with short ravels (Table 1).

\section{CONCLUSION}

The system described provides a true fluoroscopic presentation of a selected body section. It provides a rapid method for localization and selection of the plane of interest accomplishing this with significant savings in patient dose as compared to standard procedures using film. Further developments will enable the radiologist to assess pulsating or other forms of motion in a selected plane in the body. 


\section{REFERENCES}

1. Baker, V.D. and Miller, W.B.: A TV System for Electronic Radiography. Proc. of the 20th Annual Conf. on Eng. in Med. \& Biol. 10.1 (1967).

2. FrimonnmDahl, J. and Kühl, H.B.: Immediate Centering and Tomographic Cut Lacalization By Means of Roentgen Television, Acta Radiologica, 10, 236-240 (1970).

3. Baily, N.A. and Crepeau, R.L.: Capabilities of a Single--Scan TV Radiography System for Digital Data Acquisition, Investigarive Radiology (In Press). 


\section{FIGURE CAPTIONS}

Fig. 1: Planigram of the hip joint in a pelvic phantom. Recorded on film using a $12.5^{\prime \prime}$ stroke ot $65 \mathrm{kVp}$ and $100 \mathrm{mAs}$.

Fig. 2: Fluoroplanigram of the same section as shown in Fig. I photographed from face of TV monitor. Recorded using $66.25^{\prime \prime}$ stroke of $70 \mathrm{kVp}, 3.5 \mathrm{mAs}$ with 12:1 moving grid.

Fig. 3: Planigram of the right thorax of a patient with metastices originating from a primary carcinoma of the cervix. Film was recorded using a $6.25^{\text {"t }}$ stroke, $70 \mathrm{kVp}$, and $25 \mathrm{mAs}$.

Fig. 4: Fluoroplenigram of same section as shown in Fig. 3 photographed from foce of TV monitor. Recorded using a $6.25^{\prime \prime}$ stroke at $70 \mathrm{kVp}$ and $1.5 \mathrm{mAs}$. 


\section{TABLE}

SECTION THICKNESS AS A FUNCTION OF TUBE TRAVEL DISTANCE

\begin{tabular}{|c|c|c|}
\hline & \multicolumn{2}{|c|}{ SECTION THICKNESS } \\
\hline TRAVEL (in.) & FLUOROPLANIGRAPHY (mm.) & FILM PLANIGRAPHY (mm.) \\
\hline 6.25 & $<2$ & $<2$ \\
12.0 & $<2$ & $<5$ \\
18.75 & $<2$ & 5 \\
25 & $\sim 3$ & 8 \\
\hline
\end{tabular}




\section{TABLE U}

\section{EXPOSURE RATES AT $20 \mathrm{CM}$. ABOVE TABLE TOP FOR VARIOUS PLANIGRAPHIC TECHNIQUES}

\begin{tabular}{|c|c|c|c|}
\hline Kvp & mAs & Fluoroplanigraphy & Film Plonigraphy \\
\hline 65 & 100 & & $1.4 R$ \\
\hline 70 & 1.5 & $25.5 \mathrm{mR}$ & \\
\hline 70 & 25 & & $0.43 R$ \\
\hline $\begin{array}{l}70 \\
(12: 1 \text { moving grid) }\end{array}$ & 3.5 & $59.5 \mathrm{mR}$ & \\
\hline
\end{tabular}

